Jurnal Media Pertanian Vol. 4 No. 1 Tahun 2019 Hal. 19 - 25

Media Komunikasi Hasil Penelitian dan Review Literatur Bidang Ilmu Agronomi

ISSN print $2503-1279$ ISSN online $2581-1606$

\title{
PERTUMBUHAN BIBIT KOPI LIBERIKA TUNGKAL KOMPOSIT PADA BERBAGAI MEDIA TANAM
}

\author{
${ }^{1}$ Yulistiati Nengsih dan ${ }^{2}$ Yuza Defitri \\ ${ }^{1}$ Program Studi Agroteknologi, Fakultas Pertanian Universitas Batanghari \\ J1. Slamet Riyadi, Broni Jambi. 36122. Telp. +62074160103 \\ ${ }^{1}$ email korespondensi: nyulistiati@yahoo.com
}

\begin{abstract}
Abtract
Good planting media is a medium that is able to provider water and nutrients is sufficient quantities for plant growth. This can be found on soils with good air conditioning, has a solid aggregate, good water holding ability and room for sufficient rooting. Proper use of media will provide optimal growth for the plants. This study aims to determine the best planting medium to support the growth of coffe seedling Liberika Tungkal Komposit. The research was conducted in the experimental garden Pijoan, University Batanghari Jambi. From March to May 2017. The research design in this experiment was planting medium with complete randomized environmental design $(R A L)$. The treatment is : MO = plant medium $100 \%$ peat soil, $M 1=$ plant medium $100 \%$ ultisol soil, $M 2=$ planting medium $50 \%$ untisol soil $+50 \%$ rice husk charcoal, $M 3=$ planting medium $50 \%$ ultisol soil + $50 \%$ cocopeat,$M 4=$ planting medium $50 \%$ ultisol soil $+50 \%$ river sand, $M 5=$ planting medium $50 \%$ peat soil $+50 \%$ rice husk charcoal, $M 6=$ planting medium $50 \%$ peat soil + $50 \%$ cocopeat, $M 7=$ planting medium $50 \%$ peat soil $+50 \%$ river sand. Parameter observed were plant height, stem diameter, root length, crown dry weight, root dry weight, root canopy ratio, total dry weight, quality index, initial $\mathrm{pH}$ media and final $\mathrm{pH}$ media. The result showed that the ultisol $100 \%$ ultisol garden media gave the heighes seed growth value based on single parameter ie plant height, stem diameter, root lenght, crown dry weight, root dry weight, root canopy ratio, total dry weight, and initial media $\mathrm{pH}$ and treatment integrated quality index that indicates that the seed is most ready to be moved to the field.
\end{abstract}

Keywords: nurseries, plantations, coffee

\begin{abstract}
Abstrak
Media tanam yang baik adalah media yang mampu menyediakan air dan unsur hara dalam jumlah cukup bagi pertumbuhan tanaman. Hal ini dapat ditemukan pada tanah dengan tata udara yang baik, mempunyai agregat mantap, kemampuan menahan air yang baik dan ruang untuk perakaran yang cukup.Penggunaan media yang tepat akan memberikan pertumbuhan yang optimal bagi tanaman. Percobaan bertujuan untuk mengetahui media tanam yang paling baik untuk menunjang pertumbuhan bibit kopi Liberika Tungkal Komposit. Penelitian dilakukan di Kebun Percobaan Fakultas Pertanian Universitas Batanghari di Pijoan, Muaro Jambi. Percobaan dilaksanakan pada bulan Maret sampai Mei 2017. Percobaan menggunakan rancangan lingkungan acak lengkap dan rancangan perlakuan media tanam (M) sebagai berikut: $\mathrm{M}_{0}=100 \%$ gambut, $\mathrm{M}_{1}=100 \%$ tanah jenis ultisol, $\mathrm{M}_{2}=50 \%$ tanah jenis ultisol $+50 \%$ arang sekam padi, $\mathrm{M}_{3}=50 \%$ tanah jenis ultisol $+50 \%$ cocopeat, $\mathrm{M}_{4}=50 \%$ tanah jenis ultisol $+50 \%$ pasir sungai, $\mathrm{M}_{5}=50 \%$ tanah gambut $+50 \%$ arang sekam padi, $\mathrm{M}_{6}=50 \%$ tanah gambut $+50 \%$ cocopeat, $\mathrm{M}_{7}=50 \%$ tanah gambut $+50 \%$ pasir sungai. Parameter yang diamati adalah $\mathrm{pH}$ awal dan $\mathrm{pH}$ akhir media, tinggi tanaman, diameter batang, panjang
\end{abstract}


Jurnal Media Pertanian Vol. 4 No. 1 Tahun 2019 Hal. 19 - 25

Media Komunikasi Hasil Penelitian dan Review Literatur Bidang Ilmu Agronomi

ISSN print $2503-1279$

ISSN online $2581-1606$

akar, bobot kering tajuk, bobot kering akar, nisbah tajuk akar, bobot kering total dan indek kualitas. Hasil percobaan menunjukkan media tanam 100\% tanah jenis ultisol menghasilkan pertumbuhan bibit tertinggi berdasarkan parameter tunggal yaitu tinggi tanaman, diameter batang, panjang akar, bobot kering tajuk, bobot kering akar, nisbah tajuk akar, bobot kering total dan parameter terintegrasi yaitu indeks kualitas.

Kata kunci: pembibitan, perkebunan, kopi

\section{PENDAHULUAN}

Kopi merupakan salah satu hasil komoditi perkebunan yang memiliki nilai ekonomis yang cukup tinggi diantara tanaman perkebunan lainnya dan berperan penting sebagai sumber devisa negara. Kopi tidak hanya berperan penting sebagai sumber devisa melainkan juga merupakan sumber penghasilan bagi tidak kurang dari satu setengah juta jiwa petani kopi di Indonesia (Rahardjo, 2012).

Provinsi Jambi mengenal tiga jenis kopi yaitu Arabica yang tumbuh di dataran tinggi, Robusta yang tumbuh di dataran rendah, dan Liberika yang tumbuh di dataran pasang surut.Kopi liberika adalah jenis kopi yang dihasilkan oleh tanaman Coffea liberica.Kopi ini disebut-sebut berasal dari tanaman kopi liar di daerah Liberia.Padahal sebenarnya ditemukan juga tumbuh secara liar di daerah Afrika lainnya.

Faktor-faktor yang mempengaruhi pertumbuhan tanaman terdiri dari faktor internal dan faktor eksternal. Faktor internal merupakan faktor yang terdapat pada benih atau tanaman itu sendiri. Faktor eksternal merupakan faktor yang terdapat di luar benih atau tanaman, salah satu yang mempengaruhi pertumbuhan yaitu media tanam.

Penggunaan media tanam yang tepat akan memberikan kondisi lingkungan yang optimal bagi pertumbuhan tanaman. Media tanam yang baik memiliki kemampuan menyediakan air dan udara yang optimum. Menurut Thompson dan Troeh (1978) komposisi tekstur, struktur dan kandungan bahan organik di dalam suatu media menentukan baik tidaknya suatu media tanam. Hartman dan Kester (1983) menambahkan bahwa media tanam yang ideal harus memiliki syarat mempunyai aerasi dan drainase yang baik kelembaban cukup, bebas dari organisme dan bahan berbahaya, cukup hara dan bobot ringan.

Menurut Ingels (1985) media tanam yang tepat merupakan salah satu syarat keberhasilan budidaya tanaman khususnya budidaya dalam wadah. Keberhasilan pertumbuhan tanaman ditentukan oleh perkembangan akarnya. Akar tanaman hendaknya berada pada suatu lingkungan yang mampu memberikan pendukung struktural, memungkinkan absorbsi air dan ketersediaan nutrisi yang memadai. Selain itu, media tanam memungkinkan drainase dan $\mathrm{pH}$ yang baik bagi tanaman.

Pertumbuhan suatu tanaman sangat dipengaruhi oleh ketersediaan air dan unsur hara. Untuk itulah media tanam yang baik sangat diperlukan untuk mendukung pertumbuhan tanaman. Media tanam berfungsi sebagai tempat tumbuh dan berkembangnya akar serta menahan unsur hara dan air sementara waktu. Jenis dan sifat media tanam akan mempengaruhi ketersediaan unsur hara 
Jurnal Media Pertanian Vol. 4 No. 1 Tahun 2019 Hal. 19 - 25

Media Komunikasi Hasil Penelitian dan Review Literatur Bidang Ilmu Agronomi

ISSN print $2503-1279$ ISSN online $2581-1606$

dan air di daerah perakaran. Beberapa macam media berbeda pengaruhnya terhadap pertumbuhan dan hasil tanaman. Perbedaan ini berhubungan dengan daya mengikat air dan unsur hara bagi tanaman serta porositas, kelembaban dan aerasi dalam media tanam (Nicholls, 1993).

Media tanam yang baik adalah media yang mampu menyediakan air dan unsur hara dalam jumlah cukup bagi pertumbuhan tanaman. Hal ini dapat ditemukan pada tanah dengan tata udara yang baik, mempunyai agregat mantap, kemampuan menahan air yang baik dan ruang untuk perakaran yang cukup. Berbagai jenis media tanam dapat kita gunakan, tetapi pada prinsipnya kita menggunakan media tanam yang mampu menyediakan nutrisi, air, dan oksigen bagi tanaman. Penggunaan media yang tepat akan memberikan pertumbuhan yang optimal bagi tanaman.

\section{METODE PENELITIAN}

Percobaan dilaksanakan di Kebun Percobaan Fakultas Pertanian Universitas Batanghari di Pijoan, Muaro Jambi pada bulan Januari sampai Mei 2017. Bahan yang digunakan adalah bibit kopi jenis Liberika berumur 30 hari, polibag, tanah gambut, tanah ultisol, arang sekam padi, cocopeat, pasir sungai, paranet dan pupuk Phonska. Alat-alat yang digunakan adalah cangkul, meteran, kertas label, pisau, alat tulis, timbangan, oven, alat pengukur $\mathrm{pH}$, dan mikrometer.

Percobaan menggunakan rancangan lingkungan acak lengkap dan rancangan perlakuan berupa media tanam (M) sebagai berikut: $\mathbf{M}_{0}=100 \%$ gambut, $\mathrm{M}_{1}=100 \%$ tanah jenis ultisol, $\mathrm{M}_{2}=50 \%$ tanah jenis ultisol $+50 \%$ arang sekam padi, $\mathrm{M}_{3}=50 \%$ tanah jenis ultisol $+50 \%$ cocopeat, $\mathrm{M}_{4}=50 \%$ tanah jenis ultisol $+50 \%$ pasir sungai, $\mathrm{M}_{5}=50 \%$ tanah gambut $+50 \%$ arang sekam padi, $\mathrm{M}_{6}=$ $50 \%$ tanah gambut $+50 \%$ cocopeat, $\mathrm{M}_{7}=50 \%$ tanah gambut $+50 \%$ pasir sungai. Setiap unit percobaan diulang $3 \mathrm{kali}$, sehingga terdapat 24 unit satuan percobaan. Masing-masing unit percobaan terdapat 10 tanaman.

Pelaksanaan percobaan diawali dengan membersihkan areal dari gulma dan sisa akar tanaman. Tanah diratakan dan selanjutnya disusun media tanam dalam polibag sesuai dengan denah percobaan. Areal percobaan dilindungan dengan paranet untuk mengurangi intensitas cahaya sebesar $25 \%$.

Media tanam yang digunakan adalan tanah gambut, arang sekam padi, cocopeat, tanah ultisol, dan pasir sungai. Masing-masing media ditimbang sebanyak $1 \mathrm{~kg}$ lalu dicampurkan sesuai perlakuan. Media dimasukkan ke dalam polibag ukuran $30 \times 30 \mathrm{~cm}$ lalu diinkubasi selama 1 minggu.

Bibit kopi Liberika tahap serdadu umur 30 hari dipindahkan ke media tanam yang telah disiapkan. Pemindahan bibit ke polibag dilakukan dengan cara melepaskan bibit dari petakan media perkecambahan dengan menggunakan tangan serta dapat dipindahkan langsung ke media tanam. Bibit dipelihara selama 60 hari.

Pemeliharaan tanaman meliputi pemberian pupuk Phonska masing-masing 2,5 $\mathrm{g} \mathrm{polibag}^{-1}$ pada awal tanam . Penyiraman tanaman dilakukan pada pagi dan sore hari. Penyiraman tidak dilakukan bila ada hujan. Parameter yang diamati dalam percobaan ini adalah $\mathrm{pH}$ awal dan $\mathrm{pH}$ akhir media. Pengukuran $\mathrm{pH}$ awal dilakukan setelah masa inkubasi. $\mathrm{pH}$ diukur dengan $\mathrm{pH}$ meter digital. Tinggi bibit 
Jurnal Media Pertanian Vol. 4 No. 1 Tahun 2019 Hal. 19 - 25

Media Komunikasi Hasil Penelitian dan Review Literatur Bidang Ilmu Agronomi

ISSN print $2503-1279$

ISSN online $2581-1606$

diukur dari pangkal batang sampai titik tumbuh tertinggi pada umur 2 minggu setelah tanam (MST) sampai 8 MST dengan interval pengamatan 2 minggu sekali. Tinggi tanaman dikur dengan mistar. Diameter batang diukur menggunakan jangka sorong pada ketinggian $2 \mathrm{~cm}$ dari pangkal batang. Pengukuran diameter batang bersamaan dengan pengukuran tinggi tanaman. Panjang akar diukur dengan mistar dari pangkal akar sampai ujung akar. Pengukuran dilakukan pada akhir percobaan.

Pada akhir percobaan, bibit yang telah diukur tinggi dan diameter batangnya dipisahkan dalam bentuk tajuk dan akar. Selanjutnya tajuk dan akar ini dikeringkan dalam oven pada suhu $80^{\circ} \mathrm{C}$ sampai bobot konstan. Bagian tanaman yang telah kering ini ditimbang untuk mengukur parameter bobot kering tajuk, bobot kering akar, bobot kering total. Nisbah tajuk akar dikur dengan rumus sebagai berikut:

Nisbah Tajuk Akar $=\frac{\text { Bobot Kering tajuk }}{\text { Bobot Kering AKar }}$

Parameter indeks kualitas (IK) diukur pada akhir percobaan dengan mengunakan data bobot kering tajuk, bobot kering akar, tinggi tanaman, dan diameter batang. Nilai indeks kualitas dihitung dengan rumus yang dijelaskan Hendromono (1989) sebagai berikut :

Data hasil pengamatan dianalisis statistika menggunakan analisis ragam. Bila pada analisis ragam menyatakan perbedaan nyata, maka dilanjutkan dengan uji DNMRT dengan ketelitian $95 \%$.

\section{HASIL DAN PEMBAHASAN}

Tabel 1. Rata-rata pH Awal, Tinggi Bibit, Diamter Batang dan Panjang Akar Bibit Kopi Liberika pada Beberapa Media Tanam.

\begin{tabular}{|l|l|c|c|c|c|}
\hline \multirow{2}{*}{ No. } & \multicolumn{1}{|c|}{ Perlakuan } & $\begin{array}{c}\text { pH awal } \\
\text { media }\end{array}$ & $\begin{array}{c}\text { Tinggi } \\
\text { Bibit } \\
(\mathrm{cm})\end{array}$ & $\begin{array}{c}\text { Diameter } \\
\text { batang } \\
(\mathrm{cm})\end{array}$ & $\begin{array}{c}\text { Panjang } \\
\text { Akar } \\
(\mathrm{cm})\end{array}$ \\
\hline 1. & M0 (100\% tanah gambut) & $5,70 \mathrm{a}$ & $5,65 \mathrm{~b}$ & $2,41 \mathrm{ab}$ & $12,55 \mathrm{~d}$ \\
\hline $\mathbf{2 .}$ & M1 (100\% tanah ultisol) & $\mathbf{6 , 3 8 ~ c}$ & $\mathbf{5 , 7 0 ~ b}$ & $\mathbf{2 , 5 9} \mathbf{b}$ & $\mathbf{1 2 , 3 0 ~ d}$ \\
\hline 3. & $\begin{array}{l}\text { M2 (50\% tanah ultisol + 50\% } \\
\text { arang sekam padi) }\end{array}$ & $6,40 \mathrm{c}$ & $5,44 \mathrm{ab}$ & $2,39 \mathrm{ab}$ & $9,82 \mathrm{ab}$ \\
\hline 4. & $\begin{array}{l}\text { M3 (50\% tanah ultisol + 50\% } \\
\text { cocopeat) }\end{array}$ & $6,17 \mathrm{c}$ & $5,39 \mathrm{ab}$ & $2,31 \mathrm{a}$ & $8,41 \mathrm{a}$ \\
\hline 5. & $\begin{array}{l}\text { M4 (50\% tanah ultisol + 50\% } \\
\text { pasir sungai) }\end{array}$ & $6,30 \mathrm{c}$ & $4,86 \mathrm{a}$ & $2,35 \mathrm{a}$ & $9,84 \mathrm{ab}$ \\
\hline 6. & $\begin{array}{l}\text { M5 (50\% tanah gambut + 50\% } \\
\text { arang sekam padi) }\end{array}$ & $6,40 \mathrm{c}$ & $4,85 \mathrm{a}$ & $2,36 \mathrm{a}$ & $10,51 \mathrm{bc}$ \\
\hline 7. & $\begin{array}{l}\text { M6 (50\% tanah gambut + 50\% } \\
\text { cocopeat) }\end{array}$ & $5,20 \mathrm{a}$ & $5,01 \mathrm{ab}$ & $2,34 \mathrm{a}$ & $11,74 \mathrm{~cd}$ \\
\hline 8. & $\begin{array}{l}\text { M7 (50\% tanah gambut + 50\% } \\
\text { pasir sungai) }\end{array}$ & $5,77 \mathrm{c}$ & $5,34 \mathrm{ab}$ & $2,32 \mathrm{a}$ & $10,56 \mathrm{bc}$ \\
\hline
\end{tabular}

Keterangan: Angka-angka yang diikuti oleh huruf kecil yang sama berbeda tidak nyata menurut uji Duncan dengan ketelitian $95 \%$. 
Jurnal Media Pertanian Vol. 4 No. 1 Tahun 2019 Hal. 19 - 25

Media Komunikasi Hasil Penelitian dan Review Literatur Bidang Ilmu Agronomi

ISSN print $2503-1279$

ISSN online $2581-1606$

Tabel 2. Rata-rata Panjang Akar, Bobot Kering Akar, Nisbah Tajuk Akar, Bobot kering Total dan Indeks Kualitas Panjang Bibit Kopi Liberika pada Beberapa Media Tanam

\begin{tabular}{|c|c|c|c|c|c|c|}
\hline \multirow[b]{2}{*}{ No. } & \multirow[b]{2}{*}{ Perlakuan } & \multicolumn{5}{|c|}{ Parameter } \\
\hline & & $\begin{array}{c}\text { Panjang } \\
\text { akar }\end{array}$ & $\begin{array}{c}\text { Bobot } \\
\text { kering } \\
\text { akar }\end{array}$ & $\begin{array}{c}\text { Nisba } \\
\text { h } \\
\text { tajuk } \\
\text { akar }\end{array}$ & $\begin{array}{c}\text { Bobot } \\
\text { kering } \\
\text { total }\end{array}$ & $\begin{array}{c}\text { Indeks } \\
\text { kualita } \\
\text { s }\end{array}$ \\
\hline 1. & M0 (100\% tanah gambut) & $0,31 \mathrm{a}$ & $0,14 \mathrm{bc}$ & $2,31 \mathrm{a}$ & $0,45 \mathrm{a}$ & $0,09 \mathrm{~b}$ \\
\hline 2. & M1 (100\% tanah ultisol) & $\mathbf{0 , 4 1} \mathrm{b}$ & $0,18 \mathrm{c}$ & 2,31 a & 0,60 b & 0,12 c \\
\hline 3. & $\begin{array}{l}\text { M2 (50\% tanah ultisol + } \\
50 \% \text { arang sekam padi) }\end{array}$ & $0,28 \mathrm{a}$ & $0,08 \mathrm{a}$ & $3,52 \mathrm{c}$ & $0,36 \mathrm{a}$ & $0,05 \mathrm{a}$ \\
\hline 4. & $\begin{array}{l}\text { M3 (50\% tanah ultisol + } \\
50 \% \text { cocopeat) }\end{array}$ & $0,28 \mathrm{a}$ & $0,08 \mathrm{a}$ & $\begin{array}{c}3,49 \\
\mathrm{bc}\end{array}$ & $0,35 \mathrm{a}$ & $0,05 \mathrm{a}$ \\
\hline 5. & $\begin{array}{l}\text { M4 (50\% tanah ultisol + } \\
50 \% \text { pasir sungai) }\end{array}$ & $0,32 \mathrm{ab}$ & $0,14 \mathrm{bc}$ & $2,54 \mathrm{a}$ & $0,46 \mathrm{a}$ & $0,10 \mathrm{bc}$ \\
\hline 6. & $\begin{array}{l}\text { M5 (50\% tanah gambut + } \\
50 \% \text { arang sekam padi) }\end{array}$ & $0,26 \mathrm{a}$ & $0,08 \mathrm{a}$ & $3,39 \mathrm{~b}$ & $0,34 \mathrm{a}$ & $0,06 \mathrm{a}$ \\
\hline 7. & $\begin{array}{l}\text { M6 (50\% tanah gambut }+ \\
50 \% \text { cocopeat) }\end{array}$ & $0,32 \mathrm{ab}$ & $0,08 \mathrm{a}$ & $4,25 \mathrm{c}$ & $0,41 \mathrm{a}$ & $0,06 \mathrm{a}$ \\
\hline 8. & $\begin{array}{l}\text { M7 (50\% tanah gambut + } \\
50 \% \text { pasir sungai) }\end{array}$ & $0,33 \mathrm{ab}$ & $0,11 \mathrm{ab}$ & $\begin{array}{c}3,00 \\
\mathrm{ab}\end{array}$ & $0,45 \mathrm{a}$ & $0,08 \mathrm{ab}$ \\
\hline
\end{tabular}

Keterangan: Angka-angka yang diikuti oleh huruf kecil yang sama berbeda tidak nyata menurut uji Duncan dengan ketelitian $95 \%$.

\section{HASIL DAN PEMBAHASAN}

Berdasarkan data yang di peroleh dari parameter penelitian yang diamati di lapangan menunjukkan bahwa terdapat perbedaan pertumbuhan bibit kopi liberika tungkal komposit (Libtukom) yang diteliti pada penelitian ini. Hasil yang menunjukkan perbedaan tidak nyata terdapat pada parameter pengamatan tinggi tanaman, diameter batang, dan bobot kering tajuk, sedangkan hasil yang menunjukkan perbedaan nyata pada beberapa parameter pengamatan seperti panjang akar, bobot kering akar, nisbah tajuk akar, bobot kering total, indeks kualitas, $\mathrm{pH}$ media awal, dan $\mathrm{pH}$ media akhir.

Pada akhir penelitian, data yang diperoleh dari perlakuan M1 (100\% tanah ultisol) memberikan nilai pertumbuhan tertinggi terhadap perlakuan tinggi tanaman, diameter batang, bobot kering tajuk, bobot kering akar, bobot kering total, dan indeks kualitas.

Perlakuan media tanam M1 (100\% tanah ultisol) pada penelitian ini dapat meningkatkan nilai tinggi tanaman, diameter batang, bobot kering tajuk, bobot kering akar, bobot kering total, dan indeks kualitas. Hal ini disebabkan bahwa media tanam M1 (100\% tanah ultisol) mengandung unsur hara yang cukup guna menunjang pertumbuhan bibit kopi liberika tungkal komposit pada media tanam.

Media M0 (100\% tanah gambut) memberikan nilai tertinggi terhadap perlakuan panjang akar. Hal ini disebabkan bahwa pada media tanam M0 (100\% 
Jurnal Media Pertanian Vol. 4 No. 1 Tahun 2019 Hal. 19 - 25

Media Komunikasi Hasil Penelitian dan Review Literatur Bidang Ilmu Agronomi

ISSN print $2503-1279$

ISSN online $2581-1606$

tanah gambut) bahan-bahan organik mudah terurai sehingga mudah diserap oleh rambut akar tanaman dan dapat meningkatkan pertumbuhan akar.

Aplikasi media tanam M6(50\% tanah gambut $+50 \%$ cocopeat) meningkatkan nilai nisbah tajuk akar, hal ini terjadi karena unsur hara pada tanah gambut yang telah terurai dapat dengan mudah diserap oleh rambut akar sehingga membuat akar tidak terlalu beraktivitas dalam penyerapan unsur hara serta tidak terhalangnya pergerakan pertumbuhan akar. Selain itu pemberian cocopeat dapat pula menambah ketersdeiaan unsur hara pada media.

Terjadi perbedaan pengamatan $\mathrm{pH}$ awal dan $\mathrm{pH}$ akhir media, dimana perlakuan media M5 (50\% tanah gambut $+50 \%$ arang sekam padi) memberikan nilai tertinggi. Aplikasi melalui media tanam pada media M5 (50\% tanah gambut $+50 \%$ arang sekam padi) menyebabkan perubahan $\mathrm{pH}$ media tanam yang mendekati netral. Pemberian arang sekam pada media dapat meningkatkan unsur hara terutama unsur $\mathrm{Ca}$ dan $\mathrm{K}$ sehingga meningatkan jumlah kation basa dan peningkatan nilai $\mathrm{pH}$.

Pada tanah ultisol walaupun $\mathrm{pH}<6(5,70)$ akan tetapi masih dapat ditoleransi oleh bibit kopi. Diduga hal ini terkait dengan sifat adaptasi tanaman itu sendiri, seperti diketahui umumnya kopi liberika tumbuh pada lahan asam dengan nilai $\mathrm{pH}<6$ tidaklan mengganggu pertumbuhan tanaman, $\mathrm{pH}$ 5,6 sangat wajar untuk tanah-tanah jenis ultisol. Keasaman ini tidaklah terlalu rendah sehingga unsur hara makro masih tersedia untuk nmendukung pertumbuhan bibit kopi.

Pada $\mathrm{pH}$ akhir media beberapa perlakuan menunjukkan adanya peningkatan nilai keasaman ( $\mathrm{pH}$ menurun) akan tetapi pada perlakuan $\mathrm{M} 0$ tanah gambut tanpa pemberian arang sekam padi menunjukan penurunan kadar $\mathrm{pH}$ yang sangat menjauhi arah netral. Hal ini dikarenakan asam yang ada pada unsur-unsur gambut mulai terlepas dan meningkatkan keasaman media tanam. Selain itu nilai pH menunjukkan banyaknya konsentrasi ion Hidrogen $(\mathrm{H}+)$ di dalam tanah.Makin tinggi kadar ion $\mathrm{H}+$ di dalam tanah, semakin masam tanah tersebut. Sangat berbeda dengan tanah ultisol walaupun menunjukkan penurunan kadar $\mathrm{pH}$ ternyata pada $\mathrm{pH}$ akhir media tetep mendekati netral. Kondisi ini juga sebagai faktor pendukung mengapa pada tanah ultisol menghasilkan bibit lebih baik.

Indeks kualitas menunjukkan parameter integral yang menginformasikan kesiapan bibit untuk dipindahkan ke lapangan. Parameter indeks kualitas ini juga dapat memberikan informasi terkait keseimbangan pertumbuhan bibit dari sisi tajuk dan akar. Nilai indeks kualitas yang baik haruslah $\geq 0,09$.

Hasil penelitian menunjukkan perlakuan M0, M4, M1 yang menunjukkan nilai IK $\geq 0,09$ dan perlakuan M1 memberikan nilai IK yang tertinggi. Nilai IK perlakuan M1 yang tertinggi berkorelasi dengan semua parameter yang diamati, bahwa M1 memberikan nilai tertinggi dibandingkan dengan perlakuan lainnya.

Media tanam secara umum mempunyai dua fungsi yaitu sebagai tempat tumbuh dan penyuplai bahan makanan bagi kehidupan dan pertumbuhan tanaman (Gunadi, 1979). Media tanam yang tepat merupakan salah satu syarat keberhasilan budidaya tanaman, khususnya budidaya dalam wadah. Keberhasilan pertumbuhan tanaman ditentukan oleh perkembangan akarnya. Akar tanaman hendaknya berada pada suatu lingkungan yang mampu memberikan tunjangan struktural, memungkinkan absorbsi air dan ketersediaan nutrisi yang memadai. Selain itu, 
Jurnal Media Pertanian Vol. 4 No. 1 Tahun 2019 Hal. 19 - 25

Media Komunikasi Hasil Penelitian dan Review Literatur Bidang Ilmu Agronomi

ISSN print $2503-1279$ ISSN online $2581-1606$

media tanam memungkinkan drainase dan $\mathrm{pH}$ yang baik bagi tanaman (Ingels, 1985). Penelitian yang dilakukan Rahmat (2005) juga menyebutkan bahwa peubah panjang akar hanya dipengaruhi secara nyata oleh perlakuan media tanam.

Diakhir penelitian, pencampuran media tanam dengan arang sekam padi menunjukkan pertumbuhan bibit dengan nilai terendah pada beberapa parameter pengamatan. Tinggi tanaman, bobot kering tajuk, bobot kering akar, dan bobot kering total nilai terendah terdapat pada media M5 (50\% tanah gambut $+50 \%$ arang sekam padi). Sedangkan nisbah tajuk akar nilai terendah dengan pencampuran arang sekam padi terdapat pada media M2 (50\% tanah ultisol $+50 \%$ arang sekam padi)

Pengaruh kombinasi media tanam tidaklah memberikan hasil yang lebih baik bila dibandingkan dengan media tanpa kombinasi, hal ini disebabkan karena pada kombinasi media tanam seperti pasir, arang sekam padi, dan cocopeat tidaklah membantu dalam ketersediaan unsur hara, unsur hara yang tersedia pada media tanam tersebut relatif kecil. Media tanam dengan bahan-bahan tersebut menghasilkan pertumbuhan bibit yang lebih rendah dibandingkan bibit pada media tanam ultisol.

\section{KESIMPULAN}

Berdasarkan tujuan penelitian, hasil dan pembahasan, maka dapat disimpulkan bahwa media tanam 100\% tanah ultisol (M1) memberikan nilai pertumbuhan bibit tertinggi berdasarkan parameter tunggal yaitu tinggi tanaman, diameter batang, panjang akar, bobot kering tajuk, bobot kering akar, nisbah tajuk akar, bobot kering total, dan $\mathrm{pH}$ media awal serta indeks kualitas (IK) yang mengindikasikan bibit tersebut paling siap dipindahkan ke lapangan.

\section{DAFTAR PUSTAKA}

Hartman, H.T. and D.E. Kester. 1983. Plant Propagation Principles and Practices. $4^{\text {th }}$ ed. Prentice Hall. New Jersey. United State. 727 p.

Hendromono. 1989. Effect of Medium Type, NPK Fertilizer and Watering Frequency to The Growth and Quality Index of Delbargia fusca Seeding. Duta Rimba XV (105-106) 31-40.

Ingels, J.E. 1985. Ornamental Horticulture: Principles and Practices State University of New York Agricultural and Technical College. Delmar Publisher Inc.524 p.

Nicholls, RE. 1993. Hidroponik Tanaman Tanpa Tanah. Dahara Prize. Semarang. Rahardjo, Pudji. 2012. Kopi Panduan Budidaya dan Pengolahan Kopi Arabika dan Robusta. Penebar Swadaya. Jakarta.

Thompson and Troeh. 1978. Soil and Soils Fertility. Mac Millan Publishing Co., New York.698 p. 